\title{
Techno-economic and life-cycle assessment of volatile oil extracted from Aquilaria sinensis using supercritical carbon dioxide
}

\author{
Yong Ling Gwee ${ }^{\mathrm{a}, \mathrm{b}}$, Suzana Yusup ${ }^{\mathrm{a}, \mathrm{b}, *}$, Raymond R. Tan ${ }^{\mathrm{c}}$, Chung Loong Yiin ${ }^{\mathrm{d}}$ \\ ${ }^{\text {a }}$ HiCoE, Biomass Processing Cluster, Centre for Biofuel and Biochemical Research, Institute of Sustainable Building, Universiti Teknologi PETRONAS, 32610 Seri Iskandar, \\ Perak, Malaysia \\ ${ }^{\mathrm{b}}$ Chemical Engineering Department, Universiti Teknologi PETRONAS, 32610 Seri Iskandar, Perak, Malaysia \\ ${ }^{\text {c } C h e m i c a l ~ E n g i n e e r i n g ~ D e p a r t m e n t, ~ D e ~ L a ~ S a l l e ~ U n i v e r s i t y, ~} 2401$ Taft Avenue, 0922 Manila, Philippines \\ d Chemical Engineering Department, Faculty of Engineering, Computing and Science, Swinburne University of Technology, Jalan Simpang Tiga, 93350, Kuching, Sarawak, \\ Malaysia
}

\section{A R T I C L E IN F O}

\section{Keywords:}

Total capital investment

Operating cost

Profits

Environmental impact

Technology readiness level

\begin{abstract}
A B S T R A C T
Extracts of Aquilaria sinensis possess pharmacological activity that has been widely used in traditional medicines since ancient times. In this study, techno-economic assessment was conducted for extraction of volatile oil from abundant biomass (lignified ring) and resin of $A$. sinensis to evaluate their respective economic feasibility using supercritical carbon dioxide $\left(\mathrm{SC}-\mathrm{CO}_{2}\right)$ extraction in Malaysia. The assessment revealed that for a production capacity of $5280 \mathrm{~kg} / \mathrm{y}$ volatile oil, the total capital investment (TCI) was $\$ 7.11$ million from summation of fixed capital cost and working capital. In terms of operating expenditure (OPEX), the volatile oil extracted from resin and lignified ring of $A$. sinensis required \$ 81.96 million and $\$ 52.39$ million, respectively. The selling price of volatile oil from resin and lignified ring were estimated to be $\$ 0.025$ million $/ \mathrm{kg}$ and $\$ 0.0125 \mathrm{million} / \mathrm{kg}$, respectively. Both volatile oil extracted from resin and lignified ring showed a positive net profit which indicated their profitability. In addition, a cradle-to-gate analysis of life-cycle assessment (LCA) was performed, whereby the extraction process contributed the highest impact towards the environment due to its high energy consumption. Nevertheless, this study estimated that the process might reduce the environmental impacts by approximately $90 \%$ when the technology readiness levels (TRLs) reach the level of 9-10. These findings are beneficial in providing preliminary insights in terms of economic and environmental aspects for volatile oil extraction using $\mathrm{SC}-\mathrm{CO}_{2}$ technology.
\end{abstract}

\section{Introduction}

The genus of Aquilaria species which is classified under plant family of Thymelaeaceae consists of resinous heartwood known as agarwood or gaharu. The term gaharu refers to the dark, dense and fragrant resinous wood located at the inner part of stem and branch of Aquilaria trees. It possesses pharmacological function and biological activity which has been used widely for medicines, perfumes and incenses. The stem of Aquilaria trees consists of resin that has unique balsamic notes and comprises of useful ingredients for perfumery which can be extracted as volatile oil [1]. For instance, many literatures have reported on pharmaceutical benefits of resin such as anti-inflammatory, anti-toxic, sedative, laxative and treatment in digestive, respiratory and nervous systems characteristics [2,3]. The lignified ring which is the outer layer of the resin comprises of a major portion from Aquilaria trees is scrapped off in order to obtain resin that located at the inner part of the stem bark. It is usually disposed by the agriculturists after obtained the resin which indirectly contributed to the amount of wood waste. About 4.5 million $t / y$ of wood waste is generated globally [4]. Thus, utilization of the lignified ring for the extraction of volatile oil with potential beneficial compounds has high novelty in generating wealth from biomass.

Owning to high market value of volatile oil, the selection of extraction method and well-designed process are necessary to obtain maximum yield of the volatile oil. The most common extraction techniques comprise of Soxhlet extraction and hydrodistillation. Soxhlet extraction requires organic solvent leading to disadvantages, such as cost of high purity, toxicity, and residue in the extracts which could potentially affect the environment and human health. At industrial scale, hydrodistillation extraction is usually applied to extract volatile

\footnotetext{
* Corresponding author at: Chemical Engineering Department, Universiti Teknologi PETRONAS, 32610 Seri Iskandar, Perak, Malaysia.

E-mail addresses: yongling1993@gmail.com (Y.L. Gwee), drsuzana_yusuf@utp.edu.my (S. Yusup), raymond.tan@dlsu.edu.ph (R.R. Tan), cyiin@swinburne.edu.my (C.L. Yiin).
} 